\title{
Sunarsi, dkk.
}

DOI : https://doi.org/10.24843/JFU.2019.v08.i02.p03

pISSN: 2301-7716; eISSN: 2622-4607

Jurnal Farmasi Udayana, Vol 8, No 2, Tahun 2019, 73-77

\section{Pemanfaatan Buah Belimbing Wuluh (Averrhoa bilimbi L.) Sebagai Alternatif Penanganan Toxic Shock Syndrome}

\author{
Sunarsi, S. ${ }^{1}$, N.Hilma ${ }^{1}$, A.Yuningsih ${ }^{1}$ \\ ${ }^{1}$ Program Studi Farmasi, Sekolah Tinggi Ilmu Farmasi Makassar, Jl. Perintis Kemerdekaan Km 13,7, \\ Makassar, 90241 \\ E-mail : suly3698@gmail.com
}

Riwayat artikel: Dikirim: 17-06-2019; Diterima: 19-08-2019, Diterbitkan: 21-01-2020

\begin{abstract}
ABSTRAK
Toxic Shock Syndrome merupakan penyakit akut yang mengancam jiwa yang dimediasi oleh racun, biasanya dipicu oleh infeksi Staphylococcus aureus atau grup A Streptococcus (GAS), diantaranya Streptococcus pyogenes. Pemanfaatan buah belimbing wuluh dalam bentuk Infused Water dengan pemanis alami Stevia rebaudiana digunakan sebagai alternatif penanganan Toxic Shock Syndrome dengan penghambatan pada bakteri Streptococcus pyogenes. Sari buah belimbing wuluh dan liofilisatnya diujikan terhadap Streptococcus pyogenes secara In Vitro dengan variasi konsentrasi untuk melihat aktivitas antibakterinya. Infused water buah belimbing wuluh dibuat dengan metode perendaman selama 4-12 jam dikombinasikan dengan daun stevia (F1) dan gula stevia (F2) dalam $250 \mathrm{~mL}$ air matang dan dievaluasi menggunakan uji organoleptik, uji $\mathrm{pH}$, uji ALT dan MPN. Hasil penelitian menunjukkan konsentrasi yang memberikan diameter penghambatan terbesar pada uji aktivitas antibakteri sari buah belimbing wuluh dan liofilisat sari buah belimbing wuluh yaitu konsentrasi $10 \%$ dengan

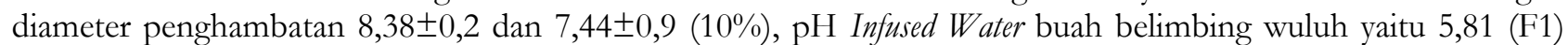
dan 6,41 (F2), uji ALT menunjukkan koloni/mL 3,1×104 (F1) dan 8,1×103 (F2), uji MPN menunjukkan hasil $92.000 \mathrm{MPN} / \mathrm{mL}$ (F1) dan $160.000 \mathrm{MPN} / \mathrm{mL}$ (F2). Dengan adanya penghambatan yang terbentuk memperlihatkan senyawa dalam buah belimbing wuluh dapat memberikan aktivitas terhadap Streptococcus pyogenes.
\end{abstract}

Kata kunci: Averrhoa bilimbi, Infused Water, Streptococcus pyogenes

\begin{abstract}
Toxic Shock Syndrome is an acute life-threatening disease mediated by poisons, usually triggered by Staphylococcus aureus infection or group A Streptococcus (GAS), including Streptococcus pyogenes. The use of Averrhoa bilimbi in the form of Infused Water with natural sweetener Stevia rebaudiana is used as an alternative treatment for Toxic Shock Syndrome with inhibition of Streptococcus pyogenes. The Averrhoa bilimbi juice and liophilisate were tested on Streptococcus pyogenes in In-Vitro with various concentrations to see their antibacterial activity. The Averrhoa bilimbi infused water was made by immersion method for 4-12 hours combined with stevia leaves (F1) and stevia sugar (F2) in $250 \mathrm{~mL}$ boiled water and evaluated using organoleptic test, $\mathrm{pH}$ test, ALT and MPN test. The results showed that the concentration that gave the largest inhibitory diameter in the antibacterial activity test for Averrhoa bilimbi juice and liophilic of Averrhoa bilimbi juice was $10 \%$ concentration with inhibition diameter of $8.38 \pm 0.2$ and $7.44 \pm 0.9(10 \%), \mathrm{pH}$ Infused Water of Averrhoa bilimbi is 5.81 (F1) and 6.41 (F2), ALT test shows colony/mL 3,1x104 (F1) and 8,1x103 (F2), MPN test shows results $92,000 \mathrm{MPN} / \mathrm{mL}$ (F1) and 160,000 MPN/mL (F2). With the inhibition formed, the compounds in Averrhoa bilimbi can provide Streptococcus pyogenes activity.
\end{abstract}

Keywords: Averrboa bilimbi, Infused Water, Streptococcus pyogenes

\section{PENDAHULUAN}

Toxic Shock Syndrome (TSS) merupakan penyakit akut yang mengancam jiwa yang dimediasi oleh racun, biasanya dipicu oleh infeksi Staphylococcus aureus atau grup A Streptococcus (GAS), yang juga disebut Streptococcus pyogenes [3]. Streptococcus pyogenes (grup A Streptococcus [GAS]) merupakan patogen yang dapat menyebabkan manifestasi klinik dengan spektrum luas pada manusia [10].

Toxic Shock Syndrome (TSS) ditandai dengan demam tinggi, ruam, hipotensi, kegagalan multiorgan (melibatkan setidaknya 3 atau lebih sistem organ), dan deskuamasi, biasanya dari 


\section{Sunarsi, dkk.}

DOI : https://doi.org/10.24843/JFU.2019.v08.i02.p03

pISSN: 2301-7716; eISSN: 2622-4607

Jurnal Farmasi Udayana, Vol 8, No 2, Tahun 2019, 73-77

telapak tangan dan telapak kaki, 1-2 minggu setelah onset penyakit akut. Data surveilans prospektif berbasis populasi dari Eropa dan Australia melaporkan bahwa infeksi GAS invasif sekitar 3 kasus / 100.000 penduduk / tahun. Antara 13 dan 15\% pasien dengan infeksi GAS invasif mengembangkan STSS dengan tingkat kematian berkisar antara 23 hingga 44\%. Data Pusat Pengendalian Penyakit (CDC) juga melaporkan sekitar 309 kasus infeksi STSS, kejadian 0,2 kasus per 100.000 penduduk / tahun, dengan tingkat kematian kasus 36\% [9].

Untuk menangani Toxic Shock Syndrome (TSS) diperlukan konsumsi obat baik sintetis atau alamiah. Seiring dengan perkembangan Ilmu Pengetahuan dan Teknologi (IPTEK) semakin banyak produksi obat sintetis, namun juga semakin banyak laporan efek samping obat sintetis sehingga membuat trend kembali ke alam untuk pengobatan meningkat. Konsumsi makanan kaya buah-buahan, sayuran dan produk makanan turunan dapat membawa manfaat kesehatan yang substansial. Dengan demikian, minat penelitian dalam antioksidan alami dan antimikroba yang ada dalam herbal, buah-buahan atau sayuran telah meningkat [4]. Salah satu buah yang memiliki kandungan senyawa yang bersifat antibakteri yaitu belimbing wuluh. Belimbing wuluh mengandung flavonoid, alkaloid, tanin, dan saponin yang bertindak sebagai antimikroba [8]. Didukung oleh penelitian yang dilakukan oleh [1], Santi dan Iga (2014), buah belimbing wuluh (Averrhoa bilimbi L.) mengandung senyawa triterpenoid, saponin, tannin, flavonoid, dan alkaloid. Daya antibakteri tanaman belimbing wuluh diperoleh dari kandungan zat aktif antara lain flavonoid, tanin, dan saponin [13]. Dilaporkan oleh penelitian Taliningrum (2015) bahwa belimbing wuluh mempunyai daya antibakteri terhadap pertumbuhan Streptococcus sanguis [12]. Hal yang sama juga dilaporkan oleh penelitian Apriliana (2013) bahwa belimbing wuluh memiliki daya hambat terhadap pertumbuhan Streptococcus mutans [2].

Pemanfaatan buah belimbing wuluh masih terbatas dibandingkan dengan ketersediannya di kalangan masyarakat [11]. Penggunaan belimbing wuluh di kalangan masyarakat masih kurang diminati karena rasa yang asam kurang diterima dan pemanfaatan buah belimbing wuluh selama ini belum banyak dilakukan. Buah belimbing wuluh selama ini hanya digunakan sebagai campuran dalam pembuatan sayur saja. Sehingga selama ini banyak buah belimbing wuluh yang dibiarkan hingga masak dan jatuh terbuang begitu saja [7]. Maka dari itu, salah satu cara untuk mengolah buah tersebut sehingga dapat dikonsumsi secara praktis yaitu dengan cara menjadikan buah belimbing wuluh menjadi Infused Water. Infused Water adalah minuman yang terdiri dari air putih yang di dalamnya dimasukkan potongan buah-buahan atau herbal, kemudian direndam beberapa waktu hingga sari dari buah tercampur dengan air sehingga manfaat dari buah yang kita masukan dapat dinikmati dengan mudah [6].

Berdasarkan latar belakang tersebut penelitian ini memanfaatkan belimbing wuluh yang diformulasi dalam bentuk Infused Water dengan pemanis alami Stevia rebaudiana yang digunakan sebagai alternatif penanganan Toxic Shock Syndrome (TSS) dengan penghambatan pada bakteri Streptococcus pyogenes.

\section{BAHAN DAN METODE}

\section{Bahan dan Alat}

Bahan yang digunakan dalam penelitian yaitu akuades, bakteri Streptococcus pyogenes, buah belimbing wuluh, daun stevia, gula stevia dan media MHA.

Peralatan yang digunakan dalam penelitian ini yaitu botol kaca, botol plastik, cawan petri, corong, erlenmeyer, Freeze Dryer, Freezer, gelas kimia, inkubator, jangka sorong, lampu spiritus, $\mathrm{pH}$ meter, pinset steril dan timbangan analitik.

\section{Determinasi}

Dilakukan determinasi tanaman belimbing wuluh di Laboratorium Biologi Universitas Negeri Makassar.

\section{Preparasi Sampel}

Sampel buah belimbing wuluh diambil di Perumahan Azzahra Daya. Sari buah belimbing wuluh dibuat dengan cara buah belimbing wuluh dicuci bersih, diperas kemudian disaring ke dalam botol kaca. Liofilisat sari buah belimbing wuluh dibuat dengan cara sari buah belimbing wuluh disimpan dalam cawan petri steril dan dikeringkan dalam Freeze Dryer selama 48 jam. Liofilisat yang dihasilkan digabungkan dan ditimbang bobotnya. 


\section{Sunarsi, dkk.}

DOI : https://doi.org/10.24843/JFU.2019.v08.i02.p03

pISSN: 2301-7716; eISSN: 2622-4607

Jurnal Farmasi Udayana, Vol 8, No 2, Tahun 2019, 73-77

\section{Uji Aktivitas Antibakteri Streptococcus pyogenes Secara In Vitro}

Uji aktivitas antibakteri sari buah belimbing wuluh dan liofilisat sari buah belimbing wuluh dilakukan dengan metode difusi agar menggunakan bakteri Streptococcus pyogenes yang diinokulasikan ke media MHA. Paper disk dicelupkan ke dalam sari buah belimbing wuluh dan liofilisat sari buah belimbing wuluh yang diencerkan dalam beberapa konsentrasi yaitu 1\%, $3 \%$, 5\%, dan 10\%. Tetrasiklin digunakan sebagai kontrol positif dan akuades sebagai kontrol negatif. Paper disk berisi larutan uji diletakkan pada cawan petri berisi media MHA yang telah diinokulasikan dengan bakteri menggunakan pinset steril, kemudian cawan petri diinkubasikan pada suhu $37^{\circ} \mathrm{C}$ selama 24 jam di inkubator. Zona hambat yang terbentuk di sekitar paper disk diamati dan diukur menggunakan jangka sorong.

\section{Pembuatan Infused Water Buah Belimbing Wuluh}

Pembuatan Infused $W$ ater buah belimbing wuluh dibuat dengan cara buah belimbing wuluh dicuci bersih, kemudian dua buah belimbing wuluh dipotong secara membujur menjadi 12 bagian dengan ketebalan pemotongan $\pm 0,5 \mathrm{~cm}$ dan ditimbang. Buah belimbing wuluh yang telah dipotong dan $500 \mathrm{mg}$ daun stevia (F1) dimasukkan ke dalam botol berisi $250 \mathrm{~mL}$ air matang kemudian ditutup dan didiamkan selama 4-12 jam di dalam kulkas. Dalam wadah berbeda, dimasukkan buah belimbing wuluh yang telah dipotong dan 2,6 gram gula stevia (F2) ke dalam botol berisi $250 \mathrm{~mL}$ air matang kemudian ditutup dan didiamkan selama 4-12 jam di dalam kulkas. Berikut spesifikasi formulasi Infused Water buah belimbing wuluh (Tabel 1):

\section{Evaluasi}

\section{a. Uji Organoleptik}

Dilakukan uji hedonik terhadap beberapa panelis untuk menilai organoleptik dari Infused Water buah belimbing wuluh.

\section{b. Uji pH}

Uji $\mathrm{pH}$ dilakukan dengan mengukur $\mathrm{pH}$ Infused Water buah belimbing wuluh menggunakan $\mathrm{pH}$ meter.

\section{c. Uji ALT dan MPN}

Pemeriksaan Infused Water buah belimbing wuluh untuk uji ALT dan uji MPN dilakukan di Balai Besar Laboratorium Kesehatan Makassar.

Tabel 1. Formulasi Infused Water Buah Belimbing Wuluh

\begin{tabular}{lll}
\hline Formulasi & Bahan Utama & Keterangan \\
\hline F1 & Air mineral & $250 \mathrm{~mL}$ \\
& Buah belimbing wuluh (12 potong) & 25 gram (dipotong dengan ukuran $\pm 0,5 \mathrm{~cm}$ secara \\
& membujur) & $500 \mathrm{mg}$ \\
F2 & Daun stevia & $250 \mathrm{~mL}$ \\
& Air mineral & 25 gram (dipotong dengan ukuran $\pm 0,5 \mathrm{~cm}$ secara \\
& Buah belimbing wuluh (12 potong) & membujur) \\
& Gula stevia & 2,6 gram \\
\hline
\end{tabular}

Tabel 2. Hasil uji aktivtas antibakteri sari buah belimbing wuluh dan liofilisat

\begin{tabular}{ccccccc}
\hline & \multicolumn{3}{c}{ Rata-Rata Diameter Zona Hambat } & \multicolumn{2}{c}{ Kontrol (mm \pm SD) } \\
Sampel Uji & $\mathbf{1} \%$ & $\mathbf{3}$. pyogenes $(\mathbf{m m} \pm \mathbf{~ S D})$ & $\mathbf{5 \%}$ & $\mathbf{1 0 \%}$ & Positif & Negatif \\
\hline Sari Buah Belimbing Wuluh & $7,09 \pm 0,2$ & $7,41 \pm 0,1$ & $8,33 \pm 0,3$ & $8,38 \pm 0,2$ & $16,27 \pm 0,03$ & - \\
$\begin{array}{c}\text { Liofilisat Sari Buah Belimbing } \\
\text { Wuluh }\end{array}$ & $7,11 \pm 0,4$ & $7,34 \pm 0,3$ & $7,05 \pm 0,8$ & $7,44 \pm 0,9$ & $16,19 \pm 0,1$ & - \\
\hline
\end{tabular}




\section{Sunarsi, dkk.}

DOI : https://doi.org/10.24843/JFU.2019.v08.i02.p03

pISSN: 2301-7716; eISSN: 2622-4607

Jurnal Farmasi Udayana, Vol 8, No 2, Tahun 2019, 73-77

\section{HASIL}

\section{Determinasi}

Diperoleh hasil determinasi tanaman

belimbing wuluh yaitu :

Kingdom : Plantae

Divisi : Magnoliophyta

Kelas : Magnoliopsida

Ordo : Geraniales

Famili : Oxalidaceae

Genus : Averrhoa

Spesies : Averrboa bilimbi $\mathrm{L}$.

\section{Uji Aktivitas Antibakteri Streptococcus pyogenes Secara In Vitro}

Hasil uji aktivitas antibakteri sari buah belimbing wuluh dan liofilisat sari buah belimbing wuluh dapat dilihat pada Tabel 2.

\section{Pembuatan Infused Water Buah Belimbing Wuluh}

Berat utuh buah belimbing wuluh yang digunakan berkisar antara 15 gram sampai 25 gram dengan panjang $4-7 \mathrm{~cm}$.

\section{Evaluasi}

\section{a. Uji Organoleptik}

Organoleptik F1 yaitu cairan berwarna cokelat muda, bau khas stevia dan memiliki rasa asam-manis. Sedangkan organoleptik F2 yaitu cairan berwarna putih keruh, bau lemah khas stevia dan memiliki rasa asam-manis. Hasil uji organoleptik dengan melakukan uji hedonik Infused Water buah belimbing wuluh dapat dilihat pada Gambar 1.

\section{b. Uji pH}

Hasil uji pH menunjukkan $\mathrm{pH}$ Infused Water yaitu 5,81 pada F1 dan 6,41 pada F2.

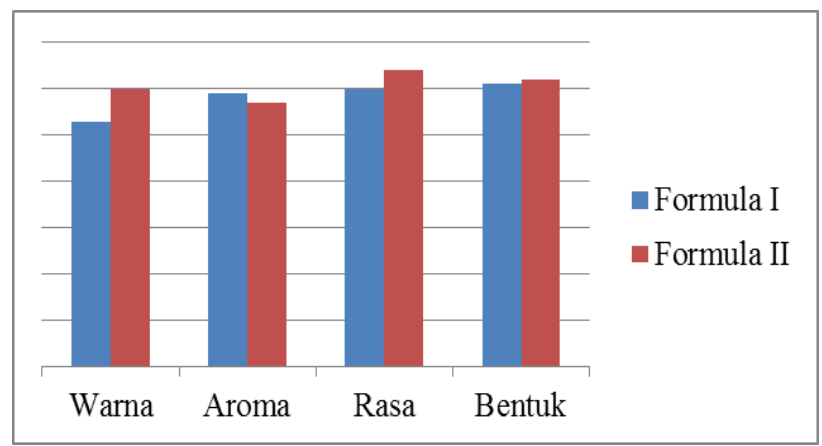

Gambar 1. Diagram Hasil Uji Hedonik Infused Water Buah Belimbing Wuluh

\section{c. Uji ALT dan MPN}

Dari hasil uji ALT Infused Water buah belimbing wuluh dalam penyimpanan 4-12 jam diperoleh jumlah koloni/mL untuk F1 yaitu $3,1 \times 10^{4}$ dan untuk F2 yaitu $8,1 \times 10^{3}$. Sedangkan hasil uji MPN yang diperoleh yaitu 92.000 $\mathrm{MPN} / \mathrm{mL}$ (F1) dan $160.000 \mathrm{MPN} / \mathrm{mL}$ (F2).

\section{PEMBAHASAN}

Sari buah belimbing wuluh dalam uji aktivitas antibakteri menunjukkan semakin besar konsentrasi sampel maka semakin besar penghambatan yang dihasilkan terhadap bakteri Streptococcus pyogenes. Konsentrasi yang memberikan diameter penghambatan terbesar dari sari buah belimbing wuluh adalah konsentrasi $10 \%$, sedangkan konsentrasi $1 \%$ memberikan diameter penghambatan terkecil. Karena buah belimbing wuluh menunjukkan aktivitas penghambatan terhadap bakteri Streptococcus pyogenes kemudian di formulasikan dalam Infused Water.

Dari hasil uji hedonik Infused Water buah belimbing wuluh, warna pada F2 lebih disukai dibanding F1, aroma pada F1 lebih disukai dibanding $\mathrm{F} 2$, rasa pada $\mathrm{F} 2$ lebih disukai dibanding F1 dan bentuk pada F2 lebih disukai dibanding F1. Dari 12 panelis, 51\% panelis lebih menyukai F2 dan 49\% menyukai F1, sehingga F2 memiliki organoleptik yang terbaik dibanding F1.

Pengujian $\mathrm{pH}$ menunjukkan bahwa Infused Water buah belimbing wuluh yang dihasilkan merupakan asam lemah. Menurut Lestari, dkk (2011) air perasan atau sari buah belimbing wuluh merupakan bahan yang bersifat asam dengan $\mathrm{pH}$ 2,3 [5]. Setelah buah belimbing wuluh diformulasikan dalam bentuk Infused Water menyebabkan keasaman buah belimbing wuluh berkurang. Berdasarkan Standar Nasional Indonesia (SNI) nomor 7388 tahun 2009 untuk air minum dalam kemasan batas maksimum untuk ALT adalah 1 x 105 sehingga $F 1$ dan F2 memenuhi persyaratan dan dapat dikonsumsi. Adapun pada hasil pengujian MPN melebihi standar yang ditetapkan oleh (SNI) nomor 7388 tahun 2009 dikarenakan waktu penyimpanan sampel telah melebihi 5x12 jam sehingga hasil yang didapatkan terdapat banyak bakteri. 


\section{Sunarsi, dkk.}

DOI : https://doi.org/10.24843/JFU.2019.v08.i02.p03

pISSN: 2301-7716; eISSN: 2622-4607

Jurnal Farmasi Udayana, Vol 8, No 2, Tahun 2019, 73-77

\section{KESIMPULAN}

Buah belimbing wuluh memiliki aktivitas penghambatan terhadap bakteri Streptococcus pyogenes sehingga dapat menjadi alternatif dalam penanganan Toxic Shock Syndrome dengan memformulasikannya dalam bentuk Infused Water yang aman dikonsumsi sehari-hari.

\section{UCAPAN TERIMAKASIH}

Penulis mengucapkan terima kasih kepada RISTEKDIKTI yang telah memberikan bantuan dana untuk pelaksanaan penelitian ini dan Sekolah Tinggi Ilmu Farmasi Makassar yang telah memberikan bantuan teknis meliputi alat, bahan serta sarana prasarana penunjang selama penelitian berlangsung.

\section{DAFTAR PUSTAKA}

[1] Andayani, R., Santi, C., dan Iga, K. "Pengaruh Ekstrak Buah Belimbing Wuluh (Averrhoa bilimbi) Terhadap Interaksi Streptococcus Sanguinis dan Streptococcus Mutans Secara In Vitro". Cakradonya Dent J, Volume 6, Nomor 2, 2014.

[2] Apriliana, N. S. M. "Daya Hambat Ekstrak Daun Belimbing Wuluh (Averrboa bilimbi Linn) Terhadap Pertumbuhan Streptococcus mutans". Bagian Mikrobiologi FKG Universitas Jember, 2013.

[3] Arifin, J. "Toxic Shock Syndrome (TSS)". Medica Hospitalia, Volume 2, Nomor 3, 2014.

[4] Das, S. "Antimicrobial and Antioxidant Activities of Green and Ripe Fruits of Averrboa carambola Linn. and Zisyphus mauritiana Lam". Asian Journal of Pharmacentical and Clinical Research, Volume 5, Nomor 3, 2012.

[5] Lestari, S., Zainal, A., dan Ekiyantini, W. "Potensi Air Perasan Belimbing Wuluh (Averrboa bilimbi L) Sebagai Bahan Alternatif Dentin Conditioner Dalam Perawatan Konservasi Gigi (In-Vitro)". Stomatognatic J.K.G Unej), Vol. 8 No. 2, 2011.

[6] Murtie, A. dan Yahya, M. Cara Asik Minum Sehat Infused Water. Jakarta : Bhuana Ilmu Populer, 2014.
[7] Rahmawati, R. D. dan Aryu, C. K. "Pengaruh Pemberian Sari Buah Belimbing Wuluh (Averrboa bilimbi L.) Terhadap Kadar Glukosa Darah Tikus Sprague Dawley". Journal of Nutrition College, Volume 4, Nomor 2, 2015.

[8] Rahmiati, A., Sri, D., dan Ana, H. M. "Daya Hambat Ektrak Etanol Buah Belimbing Wuluh (Averrboa bilimbi L.) Terhadap Pertumbuhan Staphylococcus Aureus dan Staphylococcus Epidermidis Secara In Vitro". Prosiding Seminar Nasional Publikasi HasilHasil Penelitian dan Pengabdian Masyarakat, 2017.

[9] Schimtz, M., Xavier, R., Benedikt, H., dan Jerome, P. "Streptococcal Toxic Shock Syndrome In The Intensive Care Unit". Annals of Intensive Care, Volume 8, Nomor 88, 2018.

[10] Sekizuka, dkk. "Streptococcal Toxic Shock Syndrome Caused By The Dissemination of An Invasive Emm3/ST15 Strain of Streptococcus Pyogenes". BMC Infectious Diseases, Volume 17, 2017.

[11] Sukandar, E. Y., Irda, F., dan Rizka, T. "Uji Aktivitas Antimikroba Ekstrak Etanol Buah Belimbing Wuluh (Averrboa bilimbi L.) terhadap Propionibacterium acnes, Staphylococcus epidermidis, MRSA dan MRCNS". Acta Pharmacentica Indonesia. Volume XXXIX, Nomor 3 dan 4, 2014.

[12] Taliningrum, K. K. "Perbedaan Berbagai Konsentrasi Ekstrak Etanol 70\% Daun Belimbing Wuluh (Averrboa bilimbi L.) Sebagai Bahan Obat Kumur Terhadap Hambatan Pertumbuhan Bakteri Streptococcus Sanguis in Vitro". Jurnal FKG Universitas Mubammadiyah Surakarta, 2015.

[13] Widianingrum, A. R., Nadianisa, M., dan Ardiansyah, M. S. "Perbandingan Daya Hambat Ekstrak Daun dan Buah Belimbing Wuluh (Averrhoa bilimbi) Terhadap Bakteri Penyebab Gingivitis pada Pasien dengan Ortodontik Cekat". Insisiva Dental Journal, Volume 6, Nomor 1, 2017.

This work is licensed under a Creative Commons Attribution 4.0 International License. 